\title{
Assessment of effectiveness of complex treatment of apical and marginal periodontitis with thiotriazoline and chloramphenicol ointment
}

\author{
Marta Holeyko, Volodymyr Zubachyk \\ Department of Therapeutic Dentistry, Danylo Halytsky Lviv National Medical University, Lviv, Ukraine
}

\begin{abstract}
Introduction. Chronic combined periodontal and periapical lesions have a negative impact on the human organism, since they are a source of intoxication and sensitization causing progression of infection, development of focal sequelae and secondary immunodeficiency. Problem of successful treatment of apical and marginal periodontitis is associated with a significant prevalence of these diseases, a complexity of medical procedures, a substantial proportion of failures and complications, and with a lack of long-term stability of gained results. Aim. The aim of this work was to investigate clinical effectiveness of drug formulation with thiotriazoline and chloramphenicol in the integrated treatment of combined apical and marginal periodontitis.

Meterial and methods. The condition of oral cavity of the 65 patients with combined lesions of periodontal and endodontic tissues before and after treatment was studied. Outcomes measured were X-ray examination, probing depth, OHI-S, PMA, PI, SBI indices. The complex treatment has been worked out in the patients of main group and the ointment with thiotriazoline and chloramphenicol was introduced in the scheme of periodontal treatment

Results and conclusions. Results of applied treatment indicated to the acceleration of healing process, reduction of exudation period and decrease of exacerbations frequency in the patients of main group. Clinical experience also demonstrated positive dynamic in changes of periodontal indices after the conducted treatment.
\end{abstract}

Keywords: chronic generalized periodontitis, apical periodontitis, treatment, ointment with thiotriazoline and chloramphenicol.

\section{Introduction}

Anatomical and functional interrelationship between the endodontium and periodontium causes a high probability of their simultaneous involvement in the pathological process [1]. Diseases of the periodontal tissues may have a damaging effect on the pulp or the apical periodontium through the system of apical and lateral canals, dentinal tubules [2, 3]. Finally, periodontal surgery procedures with removal of damaged cement of the tooth root can contribute to the opening of the lateral canals and dentinal tubules, resulting in the pulp destruction. Progressive periodontal pathology can lead to the pulp necrosis [4]. Chronic combined periodontal and periapical lesions have a negative impact on the human organism, since they are a source of intoxication and sensitization causing progression of infection, development of focal sequelae and secondary immunodeficiency $[5,6]$.

Problem of successful treatment of apical and marginal periodontitis is associated with a significant prevalence of these diseases, a complexity of medical procedures, a substantial proportion of failures and complications, and with a lack of long-term stability of gained results [7].

Endodontic treatment in patients with pathology of periodontal tissues is of particular importance: it is impossible to achieve a long-lasting remission and sta- 
bilization of pathological process without an appropriate endodontic treatment; on the other hand, incomplete endodontic therapy may result in the aggravation of periodontal status at the early stages of periodontitis $[8,9]$.

\section{Aim}

The aim of this work was to investigate clinical effectiveness of drug formulation with thiotriazoline and chloramphenicol [10] in the integrated treatment of combined apical and marginal periodontitis.

\section{Material and methods}

Status of oral cavity of 105 patients with apical and marginal periodontitis, who were given complex treatment and a dynamic supervision, was studied. 46 patients were diagnosed with chronic generalized periodontitis (GP) of the I stage of severity; the rest 59 patients had the GP of the II stage of severity. All patients were also diagnosed as carrying lesions of chronic apical infections, among which were granulating (45\%), fibrous (37\%) and granulomatous (28\%) periodontitis.

Clinical examination was performed according to the standard scheme. The diagnosis was made based on the complaints, anamnesis, and assessment of general and local health of patients. The anatomical features of the oral vestibule, the condition of the gingival mucous membrane, the depth of the periodontal pockets, the extent of the gingival recession and pathological tooth mobility were considered during the physical examination of the periodontal tissues. Local irritating factors such as trauma, tooth extraction, incorrect fillings, unstable dental prosthesis, plaque, calculus were also registered. The simplified oral hygiene index (OHI-S) [11], the sulcus bleeding index (SBI) [12], the papillary-marginal-alveolar index (PMA) [13], the periodontal index (PI) [14], and probing depth [15] were evaluated during the index assessment. Among the complaints of the patients with periodontitis a special attention was paid to the spontaneous pain in the causal tooth, the pain on biting, the presence of a fistula.

The duration of the disease, the occurrence of exacerbations, the previous treatment and its effectiveness were determined from the anamnesis. During the physical examination the tooth percussion sensitivity was evaluated, the alveolar bone in the root apex projection was palpated, and symptoms of angioparesis, edema and mucous membrane hyperemia were also determined. The status of the alveolar process and the periapical tissues was assessed using the $\mathrm{X}$-rays examination. Patient's examination was performed before and after treatment, and in the later periods - after 6 months.

All patients received endodontic and periodontal treatment. The patients were divided into two groups according to the given therapy. 52 patients of the main group were treated with thiotriazoline and chloramphenicol ointment after the basic therapy. 53 patients of the control group were given standard treatment.

Providing the endodontic care for patients with combined marginal and apical periodontitis was a priority task. Complex treatment of patients with different clinical forms of apical periodontits, besides mechanical tooth cleaning, disinfection and reliable obturation of the root canals, should include pharmacotherapy of the apical periodontal lesions for pharmacological correction of inflammatory process. Scheme of the endodontic treatment included the following procedures: the creation of an optimal access to the root canals, the evacuation of the degradation products, the mechanical and antiseptic root canal treatment with sodium hypochlorite $5.25 \%$. Apical therapy was finished by additional administration of the ointment with thiotriazoline and chloramphenicol into the root canal of patients from the main group, followed by closing with temporary filling; in patients from control group $0.2 \%$ chlorhexidine digluconate solution was introduced into root canal and teeth were temporarily closed.

After 2-3 days the drug preparation inside the root canal was changed into the fresh one, which was repeated 2-3 times. After the drug therapy patients without complications were exposed to obturation of root canals by sealer "Apexit" (Vivadent) and technique of cold lateral gutapercha condensation. Quality of obturation was radiographically assessed.

Periodontal treatment was performed according to the standard principles with consideration of the severity of the periodontitis and the patients' individual characteristics. Periodontal treatment included professional hygiene of oral cavity, scaling, root planning, open and closed curettage, medicamental treatment. Treatment of the control group was finished with conventional therapy. Patients in the main group were given the applications with thiotriazoline and chloramphenicol preparation in the periodontal pockets and marginal gums for 15-20 min. Number of visits depended on the severity of the inflammation.

Results of the study were statistically processed using Wilcoxon signed-rank test. 
Ethical Committee Approval: 29.10.2007, protocol number 8 .

\section{Results}

After the started complex treatment patients in the main group subjectively noticed an improvement in the periapical tissues and gums, and the inflammation reduction was determined objectively. In the next visit the situation was markedly better: pain was gradually disappearing, the exudation was decreasing, the vertical percussion was negative and the paper points used for the root canal were clean. Only 5 patients within the first 2-3 days suffered a discomfort while eating solid foods. $65 \%$ patients in the control group who were treated by traditional endodontic treatment, felt the pain when biting on the causative tooth within 3-4 days. The pain syndrome in patients with GP of the II stage lasted for 5-6 days.

The proposed method of medicated influence on lesions of apical periodontal tissues enabled us to reduce the number of visits in the main group from 4.2 to 2.4 and decrease the treatment time 1.8 times.

This was confirmed by more rapid disappearance of clinical symptoms such as spontaneous pain, pain to palpation of the gums or percussion of the teeth, symptoms of angioparesis, edema and hyperemia of the gums in projection of root apex of affected tooth; if the fistula had been present, it was quickly closed. The number of exacerbations that occurred during the treatment and after the root canal dressing in patients of the main group was much less than in the control group.

6 months after root canal treatment the mild tenderness to percussion was detected in 5 patients of control group. Control roentgenograms showed widen- ing of periodontal slit and increasing of bone loss in the apical part of the tooth root in 8 patients. Clinical picture in main group was better: complaints on discomfort and pain were absent; destructive lesions in the apical part of bone had tendency of decrease.

A positive dynamics in patients of the main group was also observed in periodontal tissues: pain, gingival hyperemia and hemorrhage were gradually decreased. Objective examinations showed marginal gingiva induration, decrease of periodontal pocket's depth and tooth mobility, color of gums was gradually changing into light pink.

We determined a positive dynamics of clinical indices. All indices, which describe the status of periodontal tissues of GP of the I stage of severity are shown in Table 1. For example, OHI-S index by Green-Vermillion in patients of the main group with chronic GP of the I stage decreased from $1.69 \pm 0.04$ points (before treatment) to $0.34 \pm 0.02$ points (after treatment). After the ointment with thiotriazoline and chloramphenicol the parameters decreased 5 times, in the patients of control group - 3 times. 6 months later OHI-S increased a little both in main group (to $0.51 \pm 0.03$ points), and in control group (to $0.84 \pm 0.03$ points) that may be explained by reduction in hygienic skills of patients.

Similar changes were also found for the SBI. Right after the treatment the $\mathrm{SBI}$ in patients of the main group significantly decreased from $1.73 \pm 0.06$ to $0.51 \pm 0.03$ points. In the control group the SBI was higher $-0.75 \pm 0.03$ points. But within 6 months it was observed the increasing of the SBI and at the moment of repeated examination the SBI in patients of the main group was $0.66 \pm 0.03$ points, in patients of control group $-0.98 \pm 0.04$ points.

Table 1. Periodontal indices in the patients with combined lesions with GP of I stage of heaviness in dynamics

\begin{tabular}{|c|c|c|c|c|c|c|}
\hline \multirow[b]{2}{*}{ Indices } & \multicolumn{2}{|c|}{ Before treatment } & \multicolumn{2}{|c|}{ After treatment } & \multicolumn{2}{|c|}{6 months after treatment } \\
\hline & $\begin{array}{c}\text { Main group } \\
n=24\end{array}$ & $\begin{array}{c}\text { Control group } \\
n=22\end{array}$ & $\begin{array}{c}\text { Main group } \\
n=24\end{array}$ & $\begin{array}{c}\text { Control group } \\
n=22\end{array}$ & $\begin{array}{c}\text { Main group } \\
n=22\end{array}$ & $\begin{array}{c}\text { Control group } \\
n=21\end{array}$ \\
\hline OHI-S ( points) & $1.69 \pm 0.04$ & $1.74 \pm 0.01$ & $\begin{array}{c}0.34 \pm 0.02 \\
t+\dagger\end{array}$ & $\begin{array}{c}0.57 \pm 0.02 \\
* * *+\dagger \dagger\end{array}$ & $\begin{array}{c}0.51 \pm 0.03 \\
t+\dagger\end{array}$ & $\begin{array}{c}0.84 \pm 0.03 \\
* * *+\dagger \dagger\end{array}$ \\
\hline PI ( points) & $1.85 \pm 0.09$ & $1.87 \pm 0.08$ & $\begin{array}{c}0.81 \pm 0.02 \\
t+\dagger\end{array}$ & $\begin{array}{c}0.99 \pm 0.02 \\
* * *+\dagger \dagger\end{array}$ & $\begin{array}{c}0.94 \pm 0.02 \\
t+\dagger\end{array}$ & $\begin{array}{c}1.03 \pm 0.02 \\
* *+\dagger \dagger\end{array}$ \\
\hline PMA (\%) & $34.46 \pm 0.35$ & $35.09 \pm 0.21$ & $\begin{array}{c}3.68 \pm 0.16 \\
t \dagger \dagger\end{array}$ & $\begin{array}{c}7.10 \pm 0.25 \\
* * *+\dagger \dagger\end{array}$ & $\begin{array}{c}4.53 \pm 0.13 \\
t \dagger \dagger\end{array}$ & $\begin{array}{c}9.63 \pm 0.16 \\
* * *+\dagger \dagger\end{array}$ \\
\hline SBI (points) & $1.73 \pm 0.06$ & $1.70 \pm 0.06$ & $\begin{array}{c}0.51 \pm 0.03 \\
t+\dagger\end{array}$ & $\begin{array}{c}0.75 \pm 0.03 \\
* *+t \dagger\end{array}$ & $\begin{array}{c}0.66 \pm 0.02 \\
t+\dagger\end{array}$ & $\begin{array}{c}0.98 \pm 0.04 \\
* *+t \dagger\end{array}$ \\
\hline Probing depth $(\mathrm{mm})$ & $2.78 \pm 0.04$ & $2.68 \pm 0.05$ & $\begin{array}{c}1.65 \pm 0.03 \\
t+\dagger\end{array}$ & $\begin{array}{c}2.04 \pm 0.03 \\
* * *+\dagger \dagger\end{array}$ & $\begin{array}{c}1.32 \pm 0.02 \\
t+\dagger\end{array}$ & $\begin{array}{c}2.27 \pm 0.03 \\
* * *+1 \dagger\end{array}$ \\
\hline
\end{tabular}

Difference between the means is signifficant at:

1. Main and control groups: ${ }^{*}-p<0.05,{ }^{* *}-p<0.01,{ }^{* * *}-p<0.001$

2. Groups before and after treatment: $t-p<0.05,+t-p<0.01,+t+-p<0.001$. 
Table 2. Periodontal indices in the patients with combined lesions with GP of II stage of severity in dynamics

\begin{tabular}{|c|c|c|c|c|c|c|}
\hline \multirow[b]{2}{*}{ Indices } & \multicolumn{2}{|c|}{ Before treatment } & \multicolumn{2}{|c|}{ After treatment } & \multicolumn{2}{|c|}{6 months after treatment } \\
\hline & $\begin{array}{c}\text { Main group } \\
n=28\end{array}$ & $\begin{array}{c}\text { Control group } \\
n=31\end{array}$ & $\begin{array}{c}\text { Main group } \\
n=28\end{array}$ & $\begin{array}{c}\text { Control group } \\
n=31\end{array}$ & $\begin{array}{c}\text { Main group } \\
n=26\end{array}$ & $\begin{array}{c}\text { Control group } \\
n=28\end{array}$ \\
\hline OHI-S ( points) & $3.24 \pm 0.04$ & $3.28 \pm 0.04$ & $\begin{array}{c}0.53 \pm 0.03 \\
t+\dagger\end{array}$ & $\begin{array}{c}0.70 \pm 0.02 \\
* * *+\dagger \dagger\end{array}$ & $\begin{array}{c}0.56 \pm 0.03 \\
t+\dagger\end{array}$ & $\begin{array}{c}1.71 \pm 0.02 \\
* * *+\dagger \dagger\end{array}$ \\
\hline PI ( points) & $3.17 \pm 0.09$ & $3.21 \pm 0.09$ & $\begin{array}{c}1.43 \pm 0.05 \\
t \dagger \dagger\end{array}$ & $\begin{array}{c}1.59 \pm 0.03 \\
* *+\dagger \dagger\end{array}$ & $\begin{array}{c}1.61 \pm 0.03 \\
t+\dagger\end{array}$ & $\begin{array}{c}1.90 \pm 0.02 \\
* * *+\dagger \dagger\end{array}$ \\
\hline PMA (\%) & $59.31 \pm 0.84$ & $58.79 \pm 0.85$ & $\begin{array}{c}8.79 \pm 0.14 \\
t \dagger \dagger\end{array}$ & $\begin{array}{c}12.22 \pm 1.14 \\
* * *+\dagger \dagger\end{array}$ & $\begin{array}{c}10.21 \pm 0.21 \\
t \dagger \dagger\end{array}$ & $\begin{array}{c}15.63 \pm 0.18 \\
* * *+\dagger \dagger\end{array}$ \\
\hline SBI (points) & $3.05 \pm 0.07$ & $3.13 \pm 0.06$ & $\begin{array}{c}0.66 \pm 0.03 \\
t+\dagger\end{array}$ & $\begin{array}{c}0.78 \pm 0.02 \\
* *+\dagger \dagger\end{array}$ & $\begin{array}{c}0.90 \pm 0.04 \\
t \dagger \dagger\end{array}$ & $\begin{array}{c}1.09 \pm 0.04 \\
{ }^{* *}+\dagger \dagger\end{array}$ \\
\hline Probing depth (mm) & $4.26 \pm 0.03$ & $4.23 \pm 0.03$ & $\begin{array}{c}2.65 \pm 0.04 \\
t+\dagger\end{array}$ & $\begin{array}{c}2.95 \pm 0.04 \\
* * *+\dagger \dagger\end{array}$ & $\begin{array}{c}2.41 \pm 0.04 \\
t+\dagger\end{array}$ & $\begin{array}{c}3.24 \pm 0.05 \\
* * *+\dagger \dagger\end{array}$ \\
\hline
\end{tabular}

Difference between the means is signifficant at:

1. Main and control groups: ${ }^{*}-p<0.05,{ }^{* *}-p<0.01,{ }^{* *}-p<0.001$

2. Groups before and after treatment: $t-p<0.05,+\dagger-p<0.01,+t+-p<0.001$.

The value of PMA, which reflects the intensity and the prevalence of inflammation in the periodontal tissues, in patients with GP of the I stage decreased too (in the main group - 9.4 times, in the control group - 5 times), 6 months after the PMA slightly increased. But difference between values of both indices shows the advantage in use of composition with thiotriazoline and chloramphenicol.

The probing depth under the effect of proposed ointment reduced from $2.78 \pm 0.04 \mathrm{~mm}$ to $1.65 \pm 0.03$ $\mathrm{mm}$, and 6 months later it was $1.32 \pm 0.02 \mathrm{~mm}$.

The PI in patients of the main group was equal to $1.85 \pm 0.09$ points before treatment, and is decreased 2.3 times after the treatment. In the control group the PI decreased 1.9 times. 6 months after the PI in the main group reduced to $0.94 \pm 0.02$ points, in the control group - to $1.03 \pm 0.02$ points. The results of the PI show a statistically significant difference.

Having analyzed the effectiveness of the treatment of patients with chronic GP of the II stage, we got the other results (Table 2 ). The $\mathrm{OHI}-\mathrm{S}$, the $\mathrm{PI}$, and the pockets depth decreased markedly, 6 months after the further decrease was significant in patients of main groups.

Use of the composition with thiotriazoline and chloramphenicol significantly improved the effectiveness of the local treatment in patients of the index group, providing the decrease of the OHI-S to $0.53 \pm 0.03$ points, whereas the $\mathrm{OHI}-\mathrm{S}$ in the control group reduced to $0.70 \pm 0.02$ points.

Comparison of the SBI in patients of the two experimental groups indicates a strong anti-inflammatory action of the proposed preparation: in patients of the main group the SBI decreased to $0.66 \pm 0.03$ points, in the control group - to $0.78 \pm 0.02$ points; after 6 months the SBI was $0.90 \pm 0.04$ vs $1.09 \pm 0.04$ points, respectively.

The PMA in the main group was $59.31 \pm 0.84 \%$ before treatment, and after treatment it changed to $8.79 \pm 0.14 \%$. In the control group it was $58.79 \pm 0.85 \%$ and $12.22 \pm 0.14 \%$, accordingly. 6 months after the treatment with thiotriazlone and chloramphenicol ointment the PMA was $10.21 \pm 0.21 \%$; in the control group it amounted to $15.63 \pm 0.18 \%$.

The probing depth in patients of the main group was $4.26 \pm 0.03 \mathrm{~mm}$ before treatment, $2.64 \pm 0.06$ $\mathrm{mm}$ - after treatment, and $2.41 \pm 0.04 \mathrm{~mm}$ - after 6 months. In patients of the control group the probing depth after 6 months was $3.24 \pm 0.05 \mathrm{~mm}$.

The dynamics of the $\mathrm{Pl}$ was also positive. The $\mathrm{PI}$ in the patients of the main group decreased to $1.43 \pm 0.05$ points, in patients of the control group to $1.59 \pm 0.03$ points. 6 months after it was equal to $1.61 \pm 0.03$ and $1.90 \pm 0.02$ points, accordingly.

\section{Conclusions}

The results of the investigations showed a high effectiveness of the proposed therapeutic scheme for combined apical and marginal periodontitis. This complex treatment including thiotriazoline and chloramphenicol ointment provided the reduction in the recovery time, as well as the positive dynamics in indices (OHI-S, $\mathrm{PBI}, \mathrm{PMA}$ and PI). Only such complex approach that includes the endodontic and periodontic treatment gives the stable positive result. Results of applied treatment indicated an acceleration of healing process, reduction of exudation period and decrease of exacerbation frequency. 


\section{Acknowledgements}

\section{Conflict of interest statement}

The authors declare that there is no conflict of interest in the authorship or publication of contribution.

\section{Funding sources}

There are no sources of funding to declare.

\section{References}

1. Volosovez TN, Mazur IP, Kabanchuk SV, Yunakova NN. Peculiarities of ethiology, pathogenesis, clinic and treatment of endo-perio lesions. Contemporary Dentistry. 2008;(4):9-14. (In Russian).

2. Orechova LU, Kudryavzeva TV, Osipova VA, Barmasheva AA. The influence of combined lesions of endodontium and periodontium on the status oral cavity. Periodontoligy. 2004;2(31):8-14. (In Russian).

3. Politun AM, Pavlyuk TD. Endo-perio lesions: pathogenesis, diagnostics, treatment tactics. Actual problems of therapeutic dentistry. 2006;(1):14-15. (In Ukrainian).

4. Briseno B. Perio-endo lesions. Clinical dentistry. 2001;(2):24-29. (In Russian).

5. Borysenko AV. Sepsis of oral cavity. Journal of practical doctor.2001;(1):8-11. (In Russian).

6. Lukoyanova NS, Kozakova VV, Palenaya UV. Indices of endogenic intoxication in patients with chronic apical periodontitis. Clinical Endodontics. 2011;(2):7-9. (In Russian).

7. Melnychuk GM, Rozhko MM, Neyko NV. Gingivitis, periodontitis, parodontosis: peculiarities of treatment: Educational applience. Ivano-Frankivsk; 2007. (In Ukrainian).

8. Silverstein L, Shatz PC, Amato AL, Kurtzman D. A guaide to diagnosing and treating endodontic and periodontal lesions. Dent Today. 1998;17(4):112.
9. Jansson LE. The influence of endodontic infection on periodontal status in mandibular molars. J Periodontol. 1998;69(12):1392-1396.

10. Zubachyk V, Holeyko M, Vaschenko O. Biopharmaceutical evaluation of semi-solid preparation with thiotriazoline and chloramphenicol. Journal of Medical Science. 2014;4(83):277-281.

11. Greene J, Vermillion J. The simplifiend oral hygeine index. J Amer Dent Ass. 1964;68(1):25.

12. Mühlemann HR, Son S. Gingival sulcus bleeding a leading symptom in initial gingivitis. Helw Odontal Acta. 1971;15(2):107-113.

13. Massler M. The PMA index of gingivitis. J Dent Res. 1949;38(6):684.

14. Russel AL. A system of classification and scoring for prevalence surveys of periodontal disease. J Dent Res. 1956;35(3):350-359.

15. Khan S, Cabanilla LL. Periodontal probing depth measurement: a review. Compend Contin Educ Dent. 2009 Jan$-F e b ; 30(1): 12-4$.

Acceptance for editing: 2015-11-10 Acceptance for publication: 2015-12-31

Correspondence address: Marta Holeyko Department of Therapeutic Dentistry Danylo Halytsky Lviv National Medical University 69 Pekarska Str., Lviv, Ukraine, 79010 phone: +38 0677698382 email: marta.holeyko@gmail.com 